\title{
Responsible Service Logic
}

\author{
Michel Léonard ${ }^{1, *}$ and Monica Drăgoicea $^{2}$ \\ ${ }^{1}$ University of Geneva, Institute of Information Service Science, Geneva, Switzerland \\ ${ }^{2}$ University Politehnica Bucharest, Faculty of Automation and Computer Science, Bucharest, Romania
}

\begin{abstract}
This paper introduces the Responsible Service logic to clarify the responsibilities of managers in the establishment of services inside society. Nowadays, managers have to foster the discovery of new Exploration and Innovation activities (E\&I). Indeed, they have to address business and societal challenges with much more consistency and responsibility, as information technologies (IT) are being infused into the development of products and services. It is a question of exploring how to rendezvous responsible management and IT potential for value co-creation. This paper considers Service Science and its two disciplinary pillars - marketing (Service-Dominant logic), and information technology (Service-IT logic). Then it introduces a third pillar, the Responsible Service logic, to fill the gap between them and, in such a way, to reinforce a cognitive continuum between all these pillars. Thus, the Responsible Service logic will concern all the co-creators of the service, although they have different skills, activities, competencies, and even belong to different entities. This is how it clarifies the real responsibilities of the managers in such a progression.
\end{abstract}

\section{Introduction}

We recognize today that the complexities in which we find ourselves in society are growing [1]. They are perceived as a reflection of the complexity of the surrounding environment [2]. Therefore, entity managers are faced with uncertainties about the direction to take, to ensure the future of their entities (such as organizations) [3].

Amid the accelerated dynamics of our society, where every single interaction is decoded through the lens of the IT, the actors are confronted with the difficult challenge of distinguishing between the two extreme approaches of technology: excess of technology and rejection of technology [4], [5]. To reestablish an acceptable and reasonable order, a reinterpretation and reconfiguration of pre-existing knowledge, as one of the greatest renewable resource [6], is needed.

To create a modern, resilient and sustainable society, scholars, managers, and ordinary citizens as well, must be engaged in informed discussions about the role of information technologies (IT) in the future of their existence [7]. However, today there are few, if any, contexts offered in this respect and, at most, citizens are exposed to opposites that generates critical dilemmas.

Technical experts and governance authorities, are confronted today with many interdependencies between technology, politics, funding, businesses, and social development. They

\footnotetext{
*e-mail: Michel.Leonard@unige.ch
} 
need expertise, tools, and new forms of governance, notably for responsible innovation, to deal with the fast pace of change induced in the society by IT [8], [9].

The Digital, with all its IT technologies, causes disruptive transformations in all sectors [10], [11]. The Digital induces transdisciplinary, trans-institutional, and even transnational responses. The critical situations in the society's progression are also of a transdisciplinary, trans-institutional, and even transnational nature. As such, the need for new frameworks of transdisciplinary research addressing societal challenges and opportunities is taking shape these days [12], [13].

Henceforth, this paper argues that it is important to explore the fundamentals of societal organization with other lens, to bring out frameworks of thought integrating concepts and consistent modes of responsible reasoning. It is not a question of making a clean slate of the recognized fundamentals on which society is based, but of analyzing them, deconstructing parts of them, and reconstructing others from the perspective of responsible entities. Eventually, this perspective will allow substantial, lasting and liberating progression for the society, within the aim of bringing cognitive serenity of all members of the society - starting with managers of businesses.

Thus, this paper is oriented towards the intelligence of the managers who are involved in digital transformations. They require a systemic approach, implying a system thinking, potentially generalizable across various value co-creating activities inside society. Service Science is potentially offering this new perspective [14]. However, to make it possible, a number of important steps should be made to address the unfamiliar domain of knowledge that must be widespread, explored, and discovered by managers. This to-be-explored knowledge domain lies between the management/social knowledge and the engineering/technological knowledge.

Further on, Section 3 describes the need of new ways of acting and new patterns of interaction between actors in the next societal order, often called Society 5.0 [15]. It describes the need of recognizing new management responsibilities, in order to concord responsibility for technology and responsibility for public benefit. The lens to observe such phenomena is provided by the two pillars of Service Science: marketing (Service-Dominant logic) and information technology (Service-IT logic).

Then, Section 4 introduces and describes the proposed third pillar of Service Science: the Responsible Service logic, to evolve the cognitive continuum of Service Science. Then it determines the management responsibilities around a service, and even those around complex services, to face the challenges of Society 5.0.

Section 5 concludes the paper by stressing the importance of Service Science to enable the co-creation of transdisciplinary, trans-institutional, and even trans-national services, necessary for societal progression. Furthermore, it highlights the importance of the new pillar, Responsible Service logic, in establishing appropriate T-shaped skills for resilient Exploration and Innovation activities (E\&I).

\section{The need and the lens}

\subsection{The need}

Today, it is acknowledged that the tremendous power of information will drive the future evolution of the society itself [16], [17], [18]. Information, appearing primarily in the raw form of data collected through all kinds of smart objects (i.e. object equipped with sensors and connected through various types of technologies), is raising the IT potentialities at all levels of the society, in new ways, hardly imagined before [19], [20], [21]. It extracts meaning out of data with Big Data (meaning "a term that adds together the collection of large volumes of 
high-velocity, heterogeneous, evolving domain data and the use of advanced techniques and models to store, retrieve, manage, process and analyze the captured information" [22], [23], relying on powerful computational algorithms and "artificial intelligence", able to augment and foster human cognition process [24], [25].

These are just a few examples of how current IT advances can influence activities, but the relations between them and the overall development of the society have not received too much attention yet. IT pushes, such as database management systems, Web-technologies, Internet of Things, cyber-physical systems, VR/ augmented reality (AR), Mixed Reality (MR), have their own role in supporting society level innovations.

This digitization of information and IT transformation of working activities, evolving from business towards inclusively defined societal activities, is starting to crystalize a new way of thinking for the realization of new economy and society. It is called Society 5.0, being known also as Japan's societal-digital transformation plan [15]. It aims the development towards a Super Smart Society, along with the 5th Science and Technology Plan supported by the Japanese government [26], [27]. It is going beyond the 4.0 thinking-based movements such as Industry 4.0 [28], [29], while drawing people together with technology in a collaborative effort of creation [30], [31].

Therefore, the perspective of Society 5.0 for innovation, growth, and well-being - by interweaving activities supported by IT - and for co-creation - through service exchange is fundamentally based on the manipulation of information. It aims to effectively connect people to information with technology, shaping the possibility to define new ways of acting and new patterns of interaction between Actors in Society.

However, Society 5.0 is not the only perspective that encourages this evolution of human society - the fifth step [32]. Today the fundamental role of the new Science of Service [33] is recognized to advance innovative systems that master service delivery on the scope of improving people's quality of life, in terms of supporting activities (transport, water, food, energy, a.s.o.), assuring well-being and health (banking, healthcare, education, a.s.o), and governing (cities, states, nations) [34]. As well, the application of IT in a service society, such as cognitive computing and computational intelligence, gives the opportunity to develop not just smarter, but also wiser, service systems [35], taking into account the new hierarchy of knowledge management for collective action [20].

To follow the perspective of Society 5.0 and smart \& wiser service systems, where people need to share information, to interact to co-create value [36], the exploration and innovation activities (E\&I) must find new stakes in the society [18]. The need for new management responsibilities must be recognized, in order to put in concordance responsibility for technology and responsibility for advancing high tech skills in services for public benefit.

\subsection{The lens}

This perspective can only be motivated by the help of Service Science, introduced by the two founding approaches Service-Dominant logic [37] and Service-IT logic [33]. Even though both of them seem to speak in the same terms on the progression of the society, they provide the two first pillars of Service Science with different mindsets: the first one from Marketing, and the second one from Information Technologies (IT). They both create a new observatory of their own domain, which enables discovering radically new knowledge. Despite their different lens, they are complementary, and they require reinforcing the cognitive continuum of knowledge between them.

\subsubsection{Service-Dominant logic}

The forerunners of Service-Dominant logic, Stephen Vargo and Robert Lusch, have introduced a disruptive way in the thought of marketing. Already before, the emergence of mar- 
keting itself created a disruptive approach in the thought of management, which has been entailed to consider the customers as determinants of products and even policy. Philip Kotler, one of the most recognized forerunners of Marketing, developed the importance of "marketing mix" composed with "four Ps": product, price, place (i.e. distribution), promotion (i.e. advertising), to establish and set up marketing policy and to influence the buyer's response [38].

Nevertheless, while the management thought has been expanded towards the customers, it stays centered on the products. Certainly, it can develop services towards customers, for instance in the context of customer relationships. Still, all these services are oriented to the practices. They do not concern the phenomenological aspects of the relation established between the firm and the customer through the product. The dominant logic of the management stays product/goods-oriented (Goods-Dominant logic).

However, these phenomenological aspects are precisely in the core of the value of a service, as the Service-Dominant logic forerunners have claimed in the 10th foundational premise (FP10): the value is always uniquely and phenomenologically determined by the beneficiary. The value is idiosyncratic, experiential, contextual, and meaning-laden [37]. This is already a big difference from the Goods-Dominant logic.

First, a service is defined as "the application of competences for the benefit of another" and as "the fundamental basis of any value creation in an exchange" [39]. Thus, the core foundational premise of Service-Dominant logic (FP1) considers that a service is the basis of all exchanges and, consequently, all economies are service economies (FP5), and all businesses are service businesses [37]. Thus, a "service" is reflecting the process of using one's resources for the benefit of another entity [40].

And so, this service-centered approach induces that "market exchange is the process of parties using their specialized knowledge for each other's benefit - that is, for mutual service provision" [39].

Service-Dominant logic establishes the primacy of operant resources (those that act upon other resources to create benefit, such as competences) over operand resources (those resources which must be acted on to be beneficial, such as natural resources, goods, and money) [41], [37]. Thus, operant resources, such as knowledge and skills, are the underlying source of value: operant resources are the fundamental source of competitive advantage (FP4).

In addition, Service-Dominant logic argues that value creating resources are not confined to the firm; customers, suppliers, and other stakeholders also constitute operant resources and contribute to value creation [42]. Then, the customer is always a co-creator of value (FP6), and the enterprise cannot deliver value, but only offer value propositions (FP7). The firm can offer its applied resources. It can collaboratively (interactively) create value following acceptance, but it cannot create/deliver value alone.

The Service-Dominant logic forerunners [37] noted how the Goods-Dominant logic was a reducer of human potentialities. Indeed, Goods-Dominant logic masks more powerful phenomena that can only be observed with intelligence. Indirect exchange masks the fundamental basis of exchange. Goods, money, and institutions mask the service-for-service nature of exchange (FP2). The Service-Dominant logic outperforms the Goods-dominant logic. Nevertheless, Goods-Dominant logic is always useful, as Service-Dominant logic forerunners recognize it in FP3: goods are distribution mechanisms for service provision. Thus, Service-Dominant logic repositions Goods-Dominant logic in the management thought with consequences in all management disciplines, and not only in marketing. 


\subsubsection{From IT-Dominant logic to Service-IT logic}

The forerunners of Service Science, Jim Spohrer, Paul Maglio, Stephen Kwan, founded Service Science based on the observation that IT, with all its technologies, actively contributes to the co-creation of values [43], [16]. It is no longer a question of considering that IT only fills services but, on the contrary, of considering it as an indispensable co-creator of values, activities, and markets.

However, these forerunners had to overcome the established dominant thought inside the IT domain, named IT-Dominant logic. Indeed, the major aim of IT-Dominant logic is to invent generic technologies, with very efficient qualities concerning for instance performance, reliability, security and safety. In the IT-Dominant logic, these technologies provide obvious solutions to problems that the society might have. So, the IT discourse is based only on technical aspects, functionalities, and visions. In such a context, managers are cognitively excluded from the IT developments, because of the nature of the IT discourse.

Thus, the forerunners established an alternative conceptual basis so that this multitude of IT innovations brings sustainable perspectives of exchanges and activities to ensure a consistent progression of the society. To begin to understand the diversity and complexity of value co-creation, the forerunners [33], [44], [34] have formulated ten fundamental concepts of Service Science: ecology, entities, interactions (networks), outcomes, value proposition-based interactions, governance mechanisms-based interactions, stakeholders, measures, resources, and access rights.

To be at the level of Service Science, IT's Body of Knowledge (BoK) should consider these 10 concepts and their interactions. However, IT-Dominant logic does not allow it. For instance, the concept of ecology is unknown in IT-Dominant logic, while in Service Science it is placed at the top of other concepts: "service system ecology is the population of all types of service system entities that interact over time to create outcomes. Types of service system entities include individuals (people) and collectives (organizations). History is the trace of all outcomes over time for all entities that interact" [34].

Thus, these forerunners paved the way for a new logic of the IT domain, called Service-IT logic, which outperforms IT-Dominant logic to consider the creation of values in the society, supported by IT. Just as Service-Dominant logic is an advance in our understanding of phenomena beyond the paradigm of Goods-Dominant logic, Service-IT logic is a similarly large advance over IT-Dominant logic.

The Service-IT logic considers many more situations in a consistent and responsible way than IT-Dominant logic can do. It requires IT to provide technologies that are resilient and sustainable not only in terms of performance, reliability, security, and safety, as in the ITDominant logic, but also in terms of services to be implemented using these IT technologies. These IT technologies must meet, notably, the following generic requirements [14]:

- They must consider not only end-users, as in IT-Dominant logic, but also managers, designers, developers;

- They must be interoperable, because a service can be supported by several IT technologies or it can be in relation with other services;

- They must be agile, because a service will evolve;

- They must support the regulatory kernel of a service, that will contain elements, such as laws, administrative and ethical rules, regulatory mechanisms, norms, scientific and technical knowledge; so that the IT technologies can allow activities to be implemented in a responsible way, because the activities will be obliged to be compliant to the elements of the regulatory kernel. 
Consequently, if the IT-Part of a service is developed using IT technologies, following the Service-IT logic, then the IT developers of the IT part have efficient tools to face the situations of interoperability, evolution, regulation. Furthermore, they can present various possibilities and their impacts to co-creators and managers: they can participate in decisions with responsibility. They are not excluded, as it is the case of IT technologies following the IT-Dominant logic.

\section{Responsible Service logic}

The intention of Responsible Service logic is to provide to the co-creators of a service, including managers and IT specialists, a cognitive context to take responsible decisions about this service. The co-creators must consider the stakes of the decisions concerning the service itself, the ecosystem, and the actors who will fulfill their activities through the service. A service is responsible if its co-creators are placed in such a cognitive context.

The aim of this paragraph is to provide a first frame of such a context.

\subsection{Issues of Responsible Service logic}

A main issue of the Responsible Service logic concerns the two pillars of Service Science: Service-dominant logic, and Service-IT logic. Traditionally, this situation of complementarity between the activity domain and the IT domain appears with regards to Goods-Dominant logic and IT-Dominant logic. It is analyzed in terms of gap, then of bridging the gap, and of aligning IT and management, for instance, at the strategy level. Such approaches are outperformed by Service Science. Indeed, Service Science, enriched by the Responsible Service logic, shows that, in fact, the "gap" is scientific knowledge, the "bridge" is a cognitive continuum, and the "alignment", in particular with its traditional meaning, masks real cognitive difficulties. All these difficulties are grounded in the necessity for establishing and maintaining concordance between all cognitive spaces involved in the service co-creation.

Thus, the Responsible Service logic sets up a cognitive continuum [14] between these two pillars, Service-dominant logic and Service-IT logic, to reinforce the cognitive complementarity between them, as figure 1 suggests.

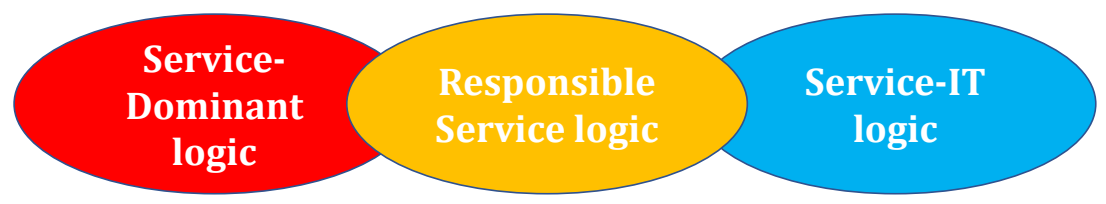

Figure 1. Cognitive continuum between Service-Dominant logic, Responsible Service logic, and Service-IT logic

Another main issue of Responsible Service logic is to consider that the co-creation of a service requires, generally, a large spectrum of knowledge. Consequently, the co-creators of a service are heterogeneous, as they have various knowledge and experiences in different domains, while fulfilling different responsibilities or tasks in various institutions.

Consequently, all these co-creators must have a common language, to enable them to discuss together, precisely and substantially, the encountered situations, and then to take responsible decisions. There is a serious candidate for such a common language: the digital information language. It is the language of data, information, or knowledge, which can be 
stored on IT media, and then can be accessible, modified, created, deleted, processed, transmitted, protected. It is accessible to all. It has been intensively used in the field of information systems engineering, in order to build conceptual models of information systems [45].

The role of the design of the service, notably its IT part, is another main issue of the Responsible Service logic. Indeed, once the design is decided, all the actors fulfilling their own activities through the service will be obliged to obey the design models that are implemented in the organization and in the IT part of the service. Thus, the responsibilities for a service must be assumed at the design level of the service.

Besides, the role of the design of the service is even more important, because a service is not a definitive solution to a problem or to an objective: it is continuously submitted to evolutions of its environment, such as modifications of laws, new IT technologies, or extension of the activities that it supports. It must evolve, its IT part must evolve, too. Such an evolution must be conducted at the design level, to enable all the co-creators, including the managers of the service, to assume responsibilities.

\subsection{Arguments for managers}

The Responsible Service logic allows the managers to assume the emerging responsibilities for all the activities around a service. To fulfill these responsibilities with intelligence, the managers have to discover some important knowledge regarding the Responsible Service logic.

\subsubsection{Service as a dipole}

The Responsible Service logic considers a service as a dipole which is built, on one side, upon the world of activities, and, on the other side, upon the digital world composed of IT systems.

The world of activities considers people who have institutional intentions, exercise responsibilities, fulfill missions, pursue objectives, carry out activities or perform tasks. The digital world considers the IT part of the service, which is composed by different systems that execute code.

Both sides share the same world, the information world, but with different lens. Notably, there are two main different facets: the human facet for the world of activities, and the artificial one for the digital world. The first one considers how information is used by people to fulfill their activities, whereas the second one focuses on how information is implemented by means of IT systems, to be accessible, updatable, protected.

The Responsible Service logic enables the emergence of a new responsibility of the managers: to set up and to maintain the concordance between the various facets of a service, notably the human facet and artificial facet. This responsibility, to avoid discrepancies, is important because these discrepancies can lead to serious cognitive misunderstandings between the co-creators and the managers of a service.

\subsubsection{Discrepancy}

The worlds of activities and the world of the Digital obey very different logics. The case of rules provides an enlightening and significant example.

The rules governing activities are described in the form of laws, regulations, formal or informal agreements, or ethics, while those governing systems are described in the form of algorithms. On the first hand, the transgression of the former requires investigations. Then, a judgment can be pronounced, taking into account the circumstances of the transgression, and 
formulating a conviction within a pre-established framework. In contrast, the transgression of the latter is immediately detected by the execution of an algorithm. And then, it is always and immediately resolved by the execution of another algorithm, programmed well before the transgression, and so, without considering the circumstances of the transgression.

This situation of discrepancy between the rules of activities and the rules of systems is not exceptional. On the contrary, it is intrinsic to this dipole that forms a service in the Responsible Service logic. It occurs continuously, everywhere, inside this dipole.

Another example of such a discrepancy is inside the dipole, which is formed by the designers of decision-support services and the decision-makers. To assume their responsibilities, effectively, they share certain common knowledge. However, they do not experience the same situations, they do not need the same information, they do not action on the same knowledge. Therefore, a person, competent in designing such services, is not necessarily a competent decision maker, and vice versa.

\subsubsection{Informational base of a service}

The Responsible Service logic provides another space, the informational base, positioned between these two worlds, so that the persons in charge of the activities and those in charge of the IT part of the service can ensure the concordance of their responsibilities and surmount discrepancies. At another level, the Responsible Service logic sets up a cognitive continuum between the Service Dominant logic and Service-IT logic.

The digital information language enables the construction of informational models, which must be actionable in both worlds, the world of activities and the Digital world. For the world of activities, these informational models are the basis to (re)think and (re)build the organization of activities, such that the obtained organization is strictly compliant with the informational models. For the world of the Digital, these informational models are the basis to (re)think and (re)build the IT part of a service, such that the IT part of a service is strictly compliant with the informational models.

Thus, these informational models enable the persons in charge of the activities and those of the Digital, to share these models, and therefore, the information they contain. Consequently, these informational models provide a critical support for the managers to establish and maintain the cognitive unity between the heterogenous co-creators.

Besides, as for information systems [46], these informational models provide the kernel of a responsible service digital platform, to support all the activities of co-creation and management of a service.

Furthermore, they also provide critical support for the actors of the service, by helping them to assimilate the role of the service inside their activities.

\subsection{A major characteristic of services: information exchange}

A major characteristic of a service, according to the first principle of Service-Dominant logic [39], is to be the fundamental basis of exchange, and exchange is recognized to be grounded on knowledge. The Responsible Service logic reinforces this perspective by explicitly addressing information and information processing, which are in the core of the exchanges, the coordination of activities, and the co-creation of the elements of the service. And so, it contributes to foster improving the creation of value. By synthesis, a major characteristic of services within the lens of Responsible Service logic is information exchange. Consequently, new management responsibilities emerge. 


\subsubsection{Exogenous and endogenous activities of a service}

The presence of an informational base inside a service (figure 2) induces new perspectives of the added value of a service in the progression of entities, such as firms, or even society. The activities of actors, executed through the service, i.e. the exogenous activities of the service, are working on information stored in the informational base, by accessing, modifying, creating, deleting it. They are intertwined at the informational level, and it is no longer interesting to distinguish beneficiaries' activities from those of the providers.

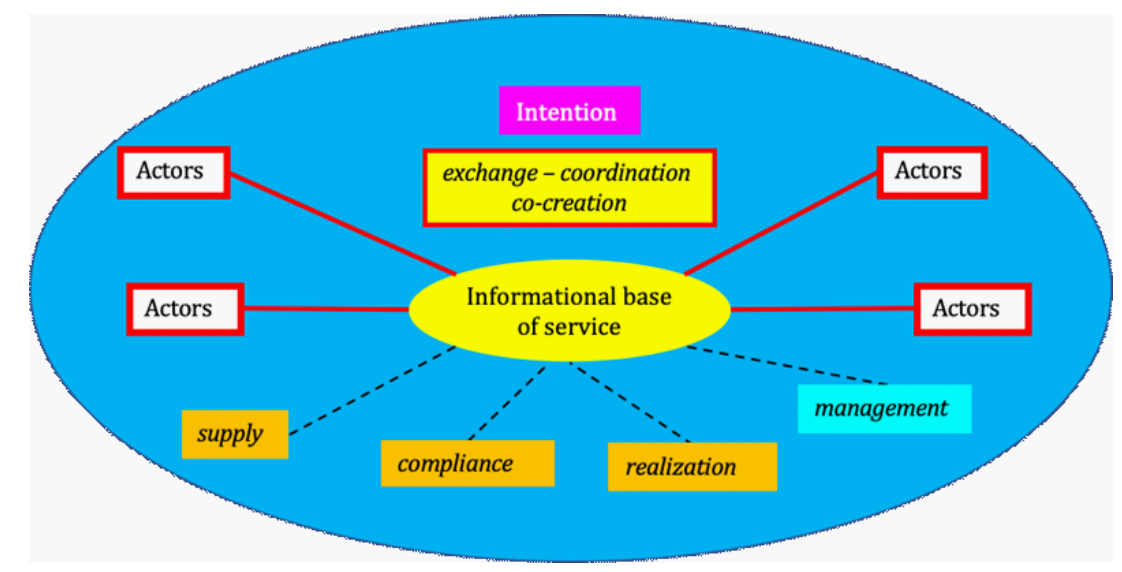

Figure 2. Service in the Responsible Service logic [14]

To be efficient, the exogenous activities need the informational base, for coherence, at any time. This coherence is assumed by the following endogenous activities:

- the realization activities concern the digital realization and organizational realization;

- the compliance activities provide the best possible guarantee to the actors that their exogenous activities comply with the laws, regulations, ethical conventions in force, as well as with the best practices, know-how, and recognized knowledge in their fields;

- the supply entity is responsible for maintaining up-to-date and reliable information that is necessary for the exogenous activities.

All the persons involved in these activities, endogenous and exogenous, are called contributors of the service. They can exchange information, coordinate their activities, and co-create new elements of the service, through the informational base of the service.

\subsubsection{Responsibilities of service management}

The management entity brings together the leaders of the endogenous and exogenous activities. It manages the endogenous activities, but in addition it fulfills the following activities, which emerge because actors' exchanges are information-based:

- It establishes the intention pursued by the service, to contribute to overcoming a critical situation of the progression of society, which, generally, concerns several sectors of society. Furthermore, this intention outlines the issues concerning transformations of institutions, firms, professions, as well as competencies and skills. It proposes explorations to create an informational base and exogenous activities, in order to overcome the situation 
described in the intention and to bring responses to the mentioned issues. It establishes a value proposition of the contribution of the service, taking into account the chances and the risks in the exploration and implementation of the service;

- It manages the setting up of the service in the involved entities, at all levels: digital, informational, and organizational;

- It oversees the concordance between the intention and the exploration process to forge the informational base of the service and then the service itself. This intention may be continuously refined in line with the discoveries emerging from the exploration;

- It is responsible for fostering the necessary evolutions of the informational base, and of the service itself, to maintain the service in concordance with the evolutions of its environment; for example, because of the introduction or modification of regulations or new information technologies;

- It is responsible for establishing the concordance between the exogenous activities and the IT part of service;

- It is responsible for fostering all efforts to assure the mandatory cognitive continuity of the activities for all actors, despite the cognitive disruption introduced by the service; notably, by fostering organizational improvements.

\subsubsection{Responsibilities of complex service management}

It is time now to consider the responsibilities of managers confronted with the perspective of Society 5.0. This perspective induces the creation of multiple services, generally constructed (i.e. created, designed, set up) independently of each other. This situation is often not sustainable, because of several drawbacks. For example, when:

- several services need the same information and each of them manages it separately, by inducing redundancy and, consequently, a source of incoherence;

- actors of a service could be much more efficient if they could access information managed by another service, through IT means;

- several actors of different services have to coordinate their activities: they cannot do it by means of their own service.

All these drawbacks disclose a more complex situation. In the perspective of Society 5.0, the intention of each service is local. A more global intention, embedded in the perspective of Society 5.0, could surmount these drawbacks. This global intention could be at the origin of a new service. However, in most of the cases, the used services cannot be stopped, and consequently, this new service could not replace the used services.

A complex service [14] is a service by itself, being composed with several services, called its basic services. It is an alliance between the service itself and its basic services. Thus, its management entity is composed of the management entities of the basic services. Notably, to surmount the previous drawbacks, it has to determine which actors of a basic service may become actors of another service through the complex service, and to foster the design and the setting up of this new capability. Furthermore, it has to foster initiatives emerging due to the complex service, to construct more efficient coordination between activities. Each of these activities is isolated inside a basic service. Moreover, it has to foster new activities, which could not have been supported previously without the complex service.

Furthermore, the management entity of a complex system is involved in the construction of its informational base. The informational base of a complex service contains information shared by the basic services. Besides, it is also involved at the digital level, where, in most 
cases, many interoperable questions arise. It has to foster all the efforts to find responses to these questions.

Consequently, first, the management entity of a complex service assumes traditional responsibilities concerning the service itself, with its intention, informational base, and IT part. Second, it assumes new responsibilities concerning the alliance between the complex service and its basic services. The latter ones are all about maintaining a cognitive concordance around the complex service, notably between the management entities of the basic services.

\section{Conclusions}

Effectively, Service Science is a serious candidate to provide a solid foundation to apprehend the challenges that the society has to surmount. It can act as a catalyst for change, if those involved, including managers, become familiar with its culture.

In this paper we present three pillars of Service Science: Service-Dominant logic, Service-IT logic, and Responsible Service logic. All these pillars belong to the same cognitive áontinuum áo ánable áelevant áiscussions áetween áo-creators áf á áervice, áven if they $h$ ave different bodies of knowledge, and if they fulfill different responsibilities. They must understand each other to co-create transdisciplinary, trans-institutional, and even transnational áervices, áhat áre necessary in áhe árogression áf áhe áociety. áhus, áhey áust acquire á áody áf ánowledge áoncerning áesponsible áervice áogic.

This is a real challenge to prolongate the already undertaken efforts to develop appropriate skills with the lens of Service Science, in particular for managers [47], [34]. This is mandatory to establish the concordance between the various responsibilities, like digital responsibility and management responsibility, facing the real stakes in the progression of society. This provides a resilient basis for enabling the Exploration and Innovation activities $(\mathrm{E} \& \mathrm{I})$ that the society needs for its fruitful progression.

Acknowledgment: We would also like to thank the reviewers for their constructive comments and valuable insights.

\section{References}

[1] J. Spohrer, K. Siddike, Y. Kohda, Rebuilding evolution: a service science perspective, in Proceedings of the 50th Hawaii International Conference on System Sciences, 1663-1672 (2017)

[2] H. A. Simon, The sciences of the artificial, 3rd Edition (MIT Press, 1996)

[3] K. Ferdows, Keeping up with growing complexity of managing global operations, Int. J. Oper. Prod. Manag. 38(2), 390-402 (2018)

[4] S. Laumer, A. Eckhardt, Why do people reject technologies: a review of user resistance theories, in Information Systems Theory. Integrated Series in Information Systems, vol. 28, Y. Dwivedi, M. Wade, S. Schneberger (Eds.) (Springer, New York, NY., 2012) 63-86

[5] V. Laurim, S. Arpaci, B. Prommegger, H. Krcmar, Computer, Whom Should I Hire? Acceptance Criteria for Artificial Intelligence in the Recruitment Process, in Proceedings of the 54th Hawaii International Conference on System Sciences, 5495-5504 (2021)

[6] N.G. Badr, M. Drăgoicea, I. Crihană, What Do We Know About Renewable Knowledge and Sustainable Societal Growth? A Scoping Review, in 17th conference of the Italian Chapter of AIS (Association for Information Systems), October 16th-17th, 2020, Pescara, Italy, http://www.itais.org/ITAIS2020_proceedings/ (2020) 
[7] S. Myeong, Y. Kim, M.J. Ahn, Smart City Strategies - Technology Push or Culture Pull? A Case Study Exploration of Gimpo and Namyangju, South Korea. Smart Cities 4(1), 41-53 (2021)

[8] Y. Kohda, Can humans learn from AI? A fundamental question in knowledge science in the AI era, in Advances in the Human Side of Service Engineering. AHFE 2020. Advances in Intelligent Systems and Computing, vol. 1208, J.C. Spohrer, C. Leitner (Eds.) (Springer, Cham., 2020) 244-250

[9] S. Barile, P. Piciocchi, C. Bassano, J.C. Spohrer, M.C. Pietronudo, Re-defining the role of artificial intelligence (AI) in wiser service systems, in Advances in Artificial Intelligence, Software and Systems Engineering. AHFE 2018. Advances in Intelligent Systems and Computing, vol. 787, T. Ahram (Eds.) (Springer, Cham., 2019) 159-170

[10] D. A. Skog, H. Wimelius, J. Sandberg, Digital disruption. Bus. Inf. Syst. Eng. Bus. Inf. Syst. Eng. 60(5), 431-437 (2018)

[11] A. Moazed, N.L. Johnson, Modern monopolies: what it takes to dominate the 21st century economy (St. Martin's Press, 2016)

[12] Addressing societal challenges using transdisciplinary research, in OECD Science, Technology and Industry Policy Papers, No. 88 (OECD Publishing, Paris, 2020) https://doi.org/10.1787/0ca0ca45-en

[13] M. Drăgoicea, L. Walletzký, L. Carrubbo, N.G. Badr, A.M. Toli, F. Romanovská, M. Ge, Service Design for Resilience: A Multi-Contextual Modeling Perspective, IEEE Access 8, 185526-185543 (2020)

[14] M. Léonard, Informational Lights from Service Science for the progression of Society (EDP Sciences, Les Ulis, 2020)

[15] i-SCOOP, From Industry 4.0 to Society 5.0: the big societal transformation plan of Japan, i-SCOOP White Paper, https://www.i-scoop.eu/industry-4-0-society-5-0/ (2017)

[16] P.P. Maglio, Smart Service Systems, Human-Centered Service Systems, and the Mission of Service Science, Service Science 7(2), ii-iii (2015)

[17] M. Léonard, A. Yurchyshyna, Towards contributive development of services, in Clean Mobility and Intelligent Transport Systems, M. Fiorini, J.C. Lin (Eds.), (IET, 2015) 1-21

[18] Y. Anzai, What Do We Need for a Smart-Service Society? Data Sharing, Organization, and Technology, in Future Services \& Societal Systems in Society 5.0, CRDS - Japan Science and Technology Agency, CRDS-FY2016-WR-13, 11-26, https://www.jst.go.jp/crds/pdf/en/CRDS-FY2016-WR-13.pdf (2016)

[19] C. Lim, K.H. Kim, M.J. Kim, J.Y. Heo, K.J. Kim, P.P. Maglio, From data to value: A nine-factor framework for data-based value creation in information-intensive services, Int. J. Inf. Manag. 39, 121-135 (2018)

[20] E. G. Carayannis, M. Del Giudice, M. Saviano, F. Caputo, Beyond big data: from smart to wise knowledge management, in Cybernetics and Systems. Social and Business Decisions, S. Barile, R. Espejo, I. Perko, M. Saviano, F. Caputo (Eds.) (Routledge, London, 2018) 297-304

[21] I.C. Ng, S.Y. Wakenshaw, The Internet-of-Things: Review and research directions, Int. J. Res. Mark. 34(1), 3-21 (2017)

[22] A.I. Torre-Bastida, J. Del Ser, I. Laña, M. Ilardia, M.N. Bilbao, S. Campos-Cordobés, Big Data for transportation and mobility: recent advances, trends and challenges, IET Int. Transport Systems 12(8), 742-755 (2018)

[23] M. A. Beyer, D. Laney, The importance of "big data": a definition, (Stamford, CT: Gartner, 2012) 2014-2018 
[24] A. Peña-Ríos, H. Hagras, G. Owusu, M. Gardner, Furthering Service 4.0: Harnessing Intelligent Immersive Environments and Systems, IEEE Syst., Man, and Cybernetics Magazine 4(1), 20-31 (2018)

[25] G. Kasparov, Deep Thinking: Where Artificial Intelligence Ends and Human Creativity Begins (John Murray, London, 2017)

[26] M. Fukuyama, Society 5.0: Aiming for a New Human-Centered Society, in Japan SPOTLIGHT, July / August 2018, 47-50, https://www.jef.or.jp/en/journal/ (2018)

[27] Y. Harayama, Society 5.0: Aiming for a New Human-centered Society. Japan's Science and Technology Policies for Addressing Global Social Challenges, Hitachi Review 66(6), 558-559 (2017)

[28] V. Potočan, M. Mulej, Z. Nedelko, Society 5.0: balancing of Industry 4.0, economic advancement and social problems, Kybernetes 50(3), 794-811 (2020)

[29] L. Granrath, Japan's Society 5.0: Going Beyond Industry 4.0, in Japan Industry News, Aug 29, 2017, https://www.japanindustrynews.com/2017/08/japans-society-5-0going-beyond-industry-4-0/ (2017)

[30] M.E. Gladden, Who will be the members of Society 5.0? Towards an anthropology of technologically posthumanized future societies, Social Sciences 8(5), 148 (2019)

[31] Hitachi Review White Paper, Future Vision for a Super Smart Society that Leads to Collaborative Creation. Toward an Era that Draws People and Technology Together, Hitachi Review 66(6), 562-563 (2017)

[32] Council for Science, Technology and Innovation, The 5th Science and Technology Basic Plan (released on January 22, 2016). https://www8.cao.go.jp/cstp/english/ basic/5thbasicplan.pdf (2016)

[33] J. Spohrer, P.P. Maglio, The emergence of service science: Toward systematic service innovations to accelerate co-creation of value, Prod. Oper. Manag. 17(3), 238-246 (2008)

[34] J. Spohrer, P.P. Maglio, Service science: Toward a smarter planet, in Introduction Service Engineering, G. Salvendy, W. Karwowski (Eds.) (Wiley, New York, 2010) 3-30

[35] J. Spohrer, C. Bassano, P. Piciocchi, M.A.K. Siddike, What makes a system smart? wise?, In Advances in The Human Side of Service Engineering, vol. 494, T. Ahram, W. Karwowski (Eds) (Springer, Cham., 2017) 23-34

[36] D. Beverungen, M. Matzner, C. Janiesch, Information systems for smart services, Inf Syst E-Bus Manage 15, 781-787 (2017)

[37] S.L. Vargo, R.F. Lusch, Evolving to a new dominant logic for marketing, J. Mark. 68(1), 1-7 (2004)

[38] P. Kotler, Marketing management: Analysis, planning, and control (Englewood Cliffs, NJ: Prentice-Hall, 1967)

[39] S.L. Vargo, R.F. Lusch, Service-dominant logic: Continuing the evolution, J. Acad. Mark. Sci. 36(1), 1-10 (2008)

[40] S.L. Vargo, R.F. Lusch, The four service marketing myths: remnants of a goods-based, manufacturing model, Journal of Service Research 6(4), 324-335 (2004)

[41] J. A. Constantin, R.F. Lusch, Understanding resource management: How to deploy your people, products, and processes for maximum productivity (McGraw-Hill School Education Group, 1994)

[42] S.L. Vargo, M.A. Akaka, Service-dominant logic as a foundation for service science: clarifications, Service Science 1(1), 32-41 (2009)

[43] P.P. Maglio, S.K. Kwan, J.C. Spohrer, Commentary - Toward a research agenda for human-centered service system innovation, Service Science 7(1), 1-10 (2015) 
[44] J. Spohrer, S.K. Kwan, Service science, management, engineering, and design (SSMED): An emerging discipline-outline \& references, Int. J. Inf. Systems in the Service Sector 1(3), 1-31 (2009)

[45] A. Olivé, Conceptual schema-centric development: a grand challenge for information systems research, in Proceedings of the International Conference on Advanced Information Systems Engineering Springer, Berlin, Heidelberg, 1-15 (2005)

[46] J. Ralyté, W. Opprecht, M. Léonard, Defining the Responsibility Space for the Information Systems Evolution Steering, in The Practice of Enterprise Modeling, Proceedings of 9th IFIP WG 8.1. Working Conference PoEM 2016, Springer, LNBIP 267, 179-193 (2016)

[47] M. M. Davis, I. Berdrow, Service science: Catalyst for change in business school curricula, IBM Systems Journal 47(1), 29-39 (2008) 